\title{
Participatory Mapping Framework and Guidelines from a GIS Perspective
}

\author{
Lisho C. Mundia \\ Department of Geo-Spatial Sciences and Technology, Namibia University of Science and Technology, Namibia
}

Copyright (C) 2016 Copyright (C) 2016 by authors, all rights reserved. Authors agree that this article remains permanently open access under the terms of the Creative Commons Attribution License 4.0 international License.

\begin{abstract}
The paper presents empirical findings on the frameworks and guidelines for participatory mapping aided by Geographical Information System (GIS) technology. It reflects the empirical benefits and challenges towards the participatory mapping, frameworks and guidelines in Land Use Planning (LUP) and the aid of GIS technology towards sustainable LUP in Namibia. The research applied a combination of approaches that include literature review, consultative meetings, Focus Group Discussions (FGDs) and Participatory Rural Appraisal (PRA). Both positive and negative impacts of the frameworks and guidelines were gathered and the results were verified to suit the participatory mapping aided by GIS technology. The research established that although frameworks and guidelines for participatory mapping aided by GIS are more favourable around the world, a comprehensive understanding is required to be applied in LUP. Although the frameworks and guidelines provide steps on how to be applied in a participatory setting, there is a need for understanding of the areas of applications and cartographical knowledge. Key recommendations include proper use of frameworks and guidelines for participatory mapping and incorporation of GIS technology in LUP.
\end{abstract}

Keywords Participatory Mapping, Land Use Planning, Frameworks, Guidelines, GIS, Namibia

\section{Introduction}

The main aim of the paper is to share the frameworks and guidelines for participatory mapping aided by GIS technology in LUP in Namibia. Various challenges such as lack of participatory methods awareness to gather local communities and experts' knowledge in LUP and the benefits such as incorporating local communities' knowledge in LUP in Namibia were explored. Different processes of incorporating local communities and experts knowledge into the implementation of Integrated Land Use Planning (ILUP) were also explored in this study.

After Namibia's independence in 1990, the Hardap region was divided into six political constituencies: Gibeon, Mariental Rural, Mariental Urban, Rehoboth Rural, Rehoboth Urban East and Rehoboth Urban West (Government of Namibia [1]). In August 2013, the Hardap region was re-demarcated with two extra constituencies (Aranos and Daweb) by the President after the fourth Delimitation Commission's recommendation to bring about better service delivery to the community of the Hardap region. However, this study was done in the six original Hardap political constituencies. This is because the practical components (participatory mapping, PRAs and FGDs) of the study were already done before the re-demarcation was implemented and there is still lack of data in the two new constituencies.

In terms of land, private farmers on a freehold basis own approximately $75 \%$ of the surface area of the Hardap region. The second largest landowner is the government that owns the extreme western part that constitutes approximately $15 \%$ of the area and is designated as part of the Namib-Naukluft Park. The central-southern part of the region is designated as communal farmland representing about $10 \%$ of the area over which traditional authorities and small-scale farmers hold control (Government of Namibia, [1]).

Government owns other small parcels of land throughout the region. Among others are about ten resettlement farms, two parcels dedicated to government agriculture and one additional protected area surrounding the Hardap Dam. Ten designated local authorities are situated in different areas within Hardap region with the largest being Rehoboth in the far north of the region and including the regional capital, Mariental, located further in the south (Mendelsohn et al. [2])."

There is a need for research about participatory integrated sustainable land use planning programmes, which would modernize the current state of land use planning in Namibia. The evaluated participatory mapping frameworks and guidelines can be used in other parts of the country in future as part of the integrated land use planning project tools. In physical and human geography, the technology of GIS, participatory mapping methods and land use planning 
application have played a vital role for many years. However, the application of proper local community participatory approaches has always been limited. Bonnett [3] stated that "the world is a material reality. Humans need to give meaning to this reality. People have traditionally used the earth's physical and human features - topography, climate and settlement - to place themselves." geography plays a critical role in development of the spatial planning such as built environment in both urban and rural communities. The planning experts usually rely on knowledge of geographical space when deciding how best to manage urban and rural land use growth. As the cities of Namibia grow and more rural land are developed, ensuring sustainable land use growth and practical sustainable land use planning management are necessary goals.

\section{Namibia and Study Area (Hardap Region)}

Namibia is located in the southwestern part of Africa and has an area of $824292 \mathrm{~km}^{2}$. Namibia shares its borders with Angola in the north, Zambia in the northeast, Botswana in the east, South Africa in the southeast and south and the Atlantic Ocean in the west. Remarkable is the area rectangle or quadric point, where four countries meet, which is unique worldwide. It actually consists of two border/area triangles, located in close proximity of each other. One is the border triangle of Botswana, the Namibia-Zambia and the area of Zambia-Botswana-Zimbabwe that is only 100 meters away.

The Namibian constitution makes provision for central, regional and local levels of government. The central government consists of the Legislature or parliament, which is the National Assembly and the National Council, the Judiciary, the Supreme, the High and the lower courts and the Executive (the President, the Cabinet and the Ministers). At regional level, there are 14 political regions as depicted in Figure 1, comprising of 121 constituencies. According to Mendelsohn et al [2]) "these were first demarcated in 1993 for the purposes of regional representation." Local governments or authorities are provided for by proclamation of settled areas as municipalities, town and villages. This means that each region is responsible for its land management activities within its area of jurisdiction.

A regional governor, who chairs a Regional Council comprising the region's councilors, heads each region. There are also long-established systems of traditional leadership or administration in communal areas. Although systems vary among the communities, most operate within some kind of hierarchical order (Mendelsohn et al [2]).

Land tenure in Namibia is based on three major categories of land ownership: private individuals and companies (freehold land); central government (communal or protected parks); and local authorities (urban land). The state manages its state land directly through its line ministries.
The study area is located in the south of Namibia, as seen on Figure 1. The Hardap region measures about 109000 $\mathrm{km}^{2}$ and the region has a population of approximately 79 000 people (Namibia Statistics Agency [4]). The region was chosen mainly due to a presence of a combination of issues that may easily lead to land disputes. These issues include, environmental issues, competitive industries who use the land for mining, agriculture and nature conservation, and an uneven distribution of infrastructure, such as boreholes, wind pumps and water canals. Flooding of the area has occurred when the sluice gates of Hardap Dam had to be opened to control dam water level. It is mainly the town of Mariental that has been affected by such flooding.

Hardap region is one of the fourteen regions of Namibia and its capital is Mariental. Hardap region stretches the entire width of Namibia, from the Atlantic Ocean in the west to Namibia's eastern national border. In the northeast, it borders Botswana, and in the southeast, it borders South Africa. Domestically, it borders the Erongo region in the northwest, Khomas region in the north central, the Omaheke region to the northeast and the //Karas region in the south (as seen on Figure 1).

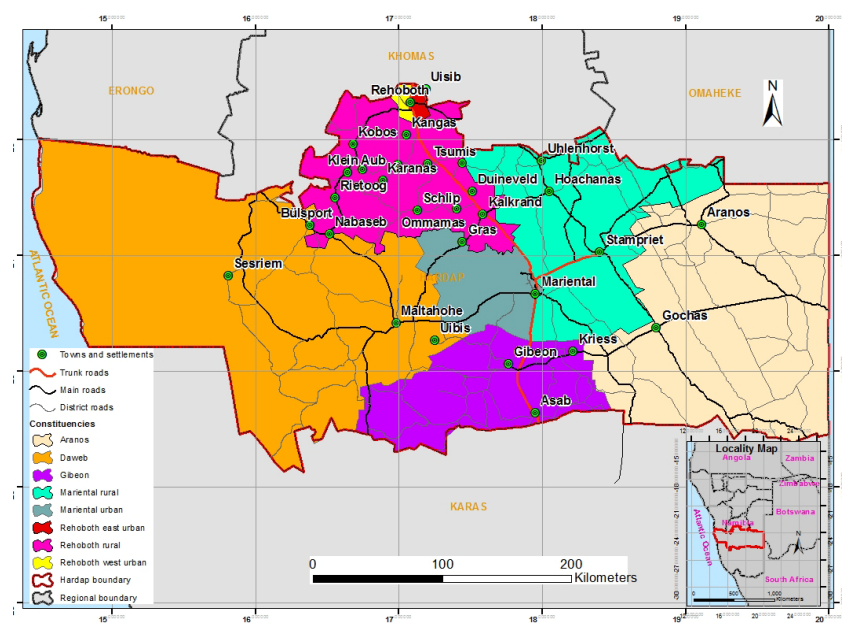

Figure 1. Study area

The participatory mapping aided by GIS for sustainable LUP was carried out in six different land portions as per constituencies of the Hardap region. The land portions where participatory mapping took place vary in land uses. Participatory mapping exercises were carried out at selected sites in each of the six constituencies of the Hardap region. These included rural, peri-urban and urban sites.

The use of the word 'Hardap' as the name of the region reflects the prominent role of the Hardap Dam in the agro-economic and tourism sectors of this region. The two major towns of the region are Rehoboth and Mariental.

\section{Methodology}

Focus group discussion refers to the style of interview that is designed for small groups (Berg [5]). The purpose of interviewing various stakeholders was to measure and draw 
on their experience and expertise to produce the frameworks and guidelines for future participatory mapping aided by GIS technology involving local community knowledge in sustainable land use management processes in Namibia.

The research objectives were realized by gathering different viewpoints, opinions and perceptions through FGDs with local communities and experts in Namibia. A focus group discussion questionnaire survey was used in a form of structured guided questions for a group discussion involving a facilitator and a group of people with knowledge and interest in a particular topic. Section A of the FGD had questions on the background information of the participants in relation to their gender and age. Section $\mathrm{B}$ of the FGD questionnaire survey dealt with land use activities and infrastructure with question of land use, infrastructure and natural phenomena availability and land dispute resolution. Section $\mathrm{C}$ of the FGD questionnaire survey was about the use of participatory mapping, with questions relating to the use of participatory mapping and maps.

Bless and Higson-Smith [6] state that "a focus group consists of between four and eight respondents who are interviewed together." Marczak and Sewell (1990 as cited in Mundia [7] explain that "a focus group typically consists of seven to ten people who are unfamiliar with each other." Clifford and Valentine [8] has different views on FGDs they maintain that "a focus group is a group of people, usually between six to twelve, who meet in an informal setting to talk about a particular topic that has been set by the researcher." This research required a minimum of seven and a maximum of ten focus group discussion participants in its separate meetings. The number of participants was determined based on models in the existing literature such as Bless and Higson-Smith [6]; Clifford and Valentine [8] and Mandara [9].

The FGDs in other studies were successful, appreciated and acceptable in participatory mapping and GIS research as confirmed by Mandara [9] in the field of planning and coordination and natural resource management. In this study, the participants were selected based on the existing constituencies in which the participants live, population variation, types of land use in the region. This selection helped in incorporating different fieldwork sites covering high settlements and towns of Hardap region with active participants in development issues. The participants were selected based on their knowledge related to and required for the research topic. The focus group participants were carefully selected according to explicitly stated criteria, which are knowledge of the study area and knowledge of the research topic.

The FGDs was conducted in unstructured and semi-structured interviews. The advantages of FGDs are that the participants are able to discuss the issues in question with each other. It also provided opportunity for participants to learn from each other and to solve important land use issues which they were confronted with. FGDs method also takes advantage of the fact that the participants naturally interact with each other and that participants are encouraged by others to participate in the discussions.

The FGD for this study required participants from experts, local communities or communal farmers of the identified sites within the six different constituencies of the Hardap region. Three meetings were held in each site within the six constituencies of the Hardap region, each lasting four hours or longer. Figure 2 depicts a picture of local people in Kalkrand participating in one of the FGD sessions.

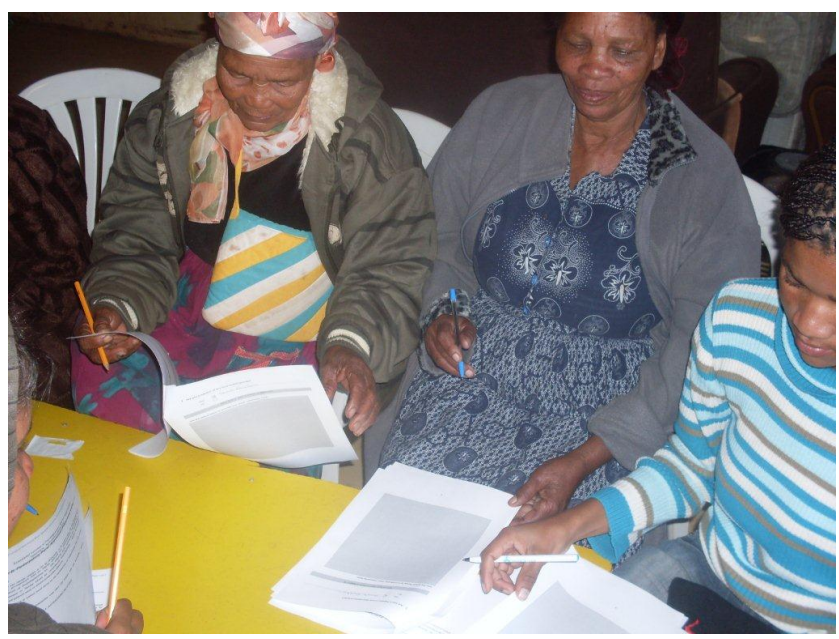

Figure 2. FGD Session in Kalkrand (Photo source: Lisho Mundia, 2011)

The FGD was divided into two sections. The first section gathered information from experts in different line ministries and various organizations. The second section was used to gather information from local communities in the Hardap region. The ministries from which experts' information were gathered includes the Ministry of Land Reform (MLR); the Ministry of Urban and Rural Development; the Ministry of Agriculture, Water and Forestry (MAWF); the Ministry of Mines and Energy (MME) and the Ministry of Environment and Tourism (MET). Other government partner organizations such as the National Planning Commission (NPC), Namibia Statistics Agency and relevant stakeholders such as farmers and researchers were also involved. The meetings helped to gather meaningful inputs, recommendations and information considered in this study as per the research aim and objectives.

Participatory GIS (PGIS) was used to solicit reality about the background and actual uses of different land. Using PGIS with communities can add value to local knowledge in support of development mechanism (Minang and McCall [10])." Participatory creation of maps by local communities for interpretation of local land uses, were done. To make the map, the participants were invited to sketch their mental maps and perceptions on the ground or on paper. The participants visualize space-related features. These may vary depending on the characteristics of the participants, for example, whether they are men or women, youth or elderly. A legend is then created and is agreed-upon by the 
participants to represent various themes such as land use and infrastructure and features such as roads, river, schools and houses. Modern mapping techniques were diffused into the study to interpret and evolve different land use data using spatial information technologies such GIS, global positioning systems (GPS), RS image analysis software and open access to spatial data and imagery via the internet.

According to Rambaldi et al. [11] "practitioners, researchers and activists in different parts of the world have tested and developed a range of integrated approaches and methodologies, which led to many innovations within what is now referred to as Participatory GIS (PGIS) practice." Nethengwe [12] also realized the importance of PGIS in the study 'Integrating Participatory GIS and Political Ecology to study Flood Vulnerability in the Limpopo Province of South Africa'. The researcher stressed that there is "the need for some form of advocacy to help communities understand and map processes that make them vulnerable and to integrate their coping strategies within a wider socio-economic and political context" Nethengwe [12]. Different participatory mapping strategies including participatory photo-mapping and sketch mapping as well as PGIS have traditionally been involved in the collection of data. These mapping strategies have specifically been used for monitoring purposes in land use development, urban development, land degradation or deforestation and urban settlement.

The study also employed PRA as a means of gathering different viewpoints, comments, inputs and information from LUP experts, and community members respectively, on use of the environment and land use in the Hardap region. This was significant in order to respond to the research objective of producing frameworks and guidelines for future participatory mapping aided by GIS technology involving local community knowledge in sustainable land use management processes in Namibia. Due to the qualitative nature of this study, PRA was used for further interaction with experts and local communities in gathering their viewpoints and knowledge. A range of qualitative data and descriptive information were collected by means of PRA methods as explained below.

The PRA was applied in this study to further gather indigenous knowledge and processes of sketch mapping, which empower local people with basic mapping skills for ILUP. Like FGD, the PRA required a minimum of seven, but not more than ten attendants in the separate meetings of local villagers, local settlers or communal farmers of the six different constituencies of the Hardap region.

PRA can be described as a family of approaches that enable people to express and analyze the realities of their lives and conditions, to plan themselves what action to take and to monitor and evaluate the results (Wageningen UR Centre for Development Innovation [13]). Kumar [14] stated that "participatory method showed a way out to participation in planning. Hence it was received with enthusiasm as even the non-literate and less articulated people could participate meaningfully in depicting their situation by making maps and diagrams and by producing plans to change their situation."

Kumar [14] stated that "PRA provided a space for many more poorer and marginalized people to articulate their problems and indicate what could be done to improve their conditions." This led to a popular surge in favor of the participatory methodology. A number of participatory approaches with varying terminologies have since come into practice over a period of time. For example, rapid rural appraisal (RRA), which later evolved into participatory rural appraisal (PRA) (Kumar [14]).

Kumar [14] further stated that "the principles of PRA have evolved over time, interestingly; new principles are still being added to the list. What distinguishes these principles is that these are induced rather than deduced, and based on practice and experience of what works and what does not work." Chambers (1997 cited in Kumar [14]) has listed "the following principles shared by both PRA and RRA:

- a reversal of learning: outsiders learning from local people;

- learning takes place rapidly and progressively;

- offsetting the usual biases of development enquiry towards the powerful and the accessible;

- optimizing trade-offs between the costs and the benefits of detailed research;

- triangulating or cross-checking between participatory methods; and

- seeking diversity".

GIS is a tool that combines ordinary descriptive information with geographical location to create meaningful, clear and attractive maps that can be applied to development needs (USAID, 2000; cited in Tripathi and Bhattarya [15]). Because of the nature of indigenous knowledge systems, GIS technology was used to facilitate the inclusion of indigenous participatory knowledge in local decision-making processes. Jordan and Shrestha, 1999, cited in Tripathi and Bhattarya [15] maintain that "there is an increasing interest in the use of GIS in a participatory context, with this development either causing alarm or being seen as providing a potentially valuable tool." In this study, a GIS was used to compile, among others, base maps that the community members used during participatory mapping processes to sketch on different land uses and different land use maps. Furthermore, design and compile a geodatabase composed of shapefiles, pre-prepared maps, imagery, participatory sketch and photo-maps was created using GIS.

Participatory mapping and other planning tools should be seen as sets of methods to help understand problematic situations in certain areas and to provide the foundation for development planning. The starting point of applying participatory planning approaches is gathering knowledge of the local people. The aim of applying such planning tools should be the creation of frameworks for communication 
and learning. Some important participatory planning tools are sketch mapping, transect walking, FGDs and semi-structured interviews. While FGD initially was developed mainly as an alternative to information collection by questionnaire surveys, PRA also devotes the planning responsibilities and the enhancement of decision-making process to the villagers. Outsiders such as researchers are supposed to act as catalysts in processes of participatory LUP.

Local communities want to have an integral and meaningful role in making decisions about their own future. The growing bodies of international law, fiscal and policies from many countries support an increasing interest in understanding the natural, cultural, and spiritual world of local communities (Emery [16]). Land development projects are beginning to include traditional knowledge in LUP and implementation when local communities are affected directly or indirectly. The frameworks and guidelines capitalize on that informed interest. Emery [16] is of the opinion that frameworks and guidelines should recommend that all stakeholders be given the opportunity to provide and accumulate wisdom from people who lived for uncounted generations on the same land.

\section{Context on Frameworks and Guidelines for Participatory Mapping in Namibia}

Literature can illustrate the value of information, show where to find data, and teach how to do research. However, there is little written to provide any guidelines for actually using information to achieve success. Most of the existing literature on participatory mapping and GIS for ILUP can be grouped into three clusters: individual, community and action success stories (Craig \& Elwood [17]).

In Namibia presently, due to the socio-political situation of the country, land resources are mostly used and managed by individual land users, without much consideration for the welfare and future of the wider population. To date, no legal frameworks, guidelines or policy has been developed for participatory mapping in the process of integrated regional LUP in Namibia. As there is no national framework for ILUP, the land use planning takes place in an uncoordinated and isolated manner. The National Land Policy provides for the mandate of coordinated LUP to be done by MLR, but no decisive measures or guidance are given by the policy on these plans. The National Development Goals (NDGs) encourage the integrated regional land use plans to be produced, monitored and updated for the regions in Namibia.

There is a wide variety of stakeholders and institutions involved in LUP and land management in Namibia. These include line ministries, the respective regional councils, the Constituency Development Committees, the Village Development Committees, the traditional authorities, the land and farming committees, the conservancies and the community forests (Government of Namibia [18]). Combined with the lack of a national LUP policy and participatory LUP guidelines, the result is that LUP and management is not coordinated and sectorally driven.

According to Amler et al [19] "the implementation of the plan is the real and original task of the target population. External support should only consist of friendly advice and the provision of materials as well as specialized know-how, which would otherwise not be accessible or affordable to the target group." To this end, the guidelines and frameworks are of a technical nature and are meant to guide relevant institutions and authorities in LUP activities at village, district and national level (Venema et al. [20]). The Government of Namibia [18] emphasized that the following are "the main gaps in the policy and legal frameworks affecting ILUP and management in Namibia:

- the lack of an existing approved national LUP Policy, and the implementation of land use plans;

- the lack of community control and authority over common grazing lands;

- the lack of clarity on group tenure over communal land;

- the lack of a common national policy on community-based natural resource management."

Participatory mapping and GIS are some of the major technologies to be incorporated into the processes of ILUP in Namibia. Globally, emphasis on land conflict identification, land conflict management, as well as land development potential has been identified and monitored using appropriate tools and technologies such as participatory mapping and GIS. One other important key element for proper sustainable LUP is to take into consideration the involvement of all stakeholders such as local communities, government experts, researchers and officials of non-governmental organizations in order to help increase the representation of appropriate views in the implementation of future ILUP projects in the Namibian context. A good representation of all stakeholders in LUP will integrate the broad views, perceptions and opinions of the society on future land uses that would directly have an effect on their livelihoods. In this study, a bottom-up approach to sustainable LUP was applied using participatory mapping, PRA and FGDs with local participants and stakeholders. Because such a holistic approach is the first of its kind in Namibia, there is a need to document the conceptualized frameworks and guidelines during the whole process for future reference.

The final product of participatory mapping aided by GIS can serve as a benchmark for future LUP in different regions in Namibia and elsewhere. Some flexibility will be required in order to capture new dynamics and characteristics within and among different areas of the country. 


\section{Results}

The frameworks and guidelines were derived from an empirical study. The frameworks and guidelines for successful participatory mapping aided by GIS for LUP are imperative for consideration in future LUP in Namibia. The research produced the frameworks and guidelines for gathering local people's knowledge in integrated land use plans for consideration by all responsible government ministries and organizations. The frameworks and guidelines should not be seen as enforced steps in the process of the implementation of ILUP, but as a contribution to many existing guidelines of how to incorporate local communities' knowledge in LUP activities. The frameworks and guidelines for participatory mapping aided by GIS were done in accordance with the decentralized administration system of Namibia. Based on the guidelines, the research also produced a GIS database for LUP using the Geopublisher software.

Table 1 provides the frameworks and guidelines for participatory mapping aided by GIS in LUP. The guidelines were derived from FGDs and participatory mapping carried out in difference parts of the Hardap region during the study. FGDs, PRA and participatory mapping are participatory approaches that can be used to generate non-spatial and spatial data, which can be captured in a GIS. Spatial data can be transferred into a GIS for detailed data processing, analyses, updating, manipulation and presentation of such data as meaningful information to meet specific objectives. The frameworks and guidelines of conducting ILUP were proposed to have four different frameworks which are described in Table 1. The frameworks in the table provide the base for the major activities within the broad participatory framework. The guidelines outline specific activities to be carried out within the frameworks.

The frameworks and guidelines presented in Table 1 were used and compiled after conducting participatory mapping meetings as they were derived from the empirical study. The third and fourth frameworks were not part of the study. However, the third framework was tested by scanning one participatory map and digitizing the map to produce a GIS map. The fourth framework was prepared once the study was completed and the participatory sketch and photo-maps were accepted by the researcher for this study, since these frameworks requires giving feedback to the local community.

The participatory mapping frameworks and guidelines are based on four common principles:

- land-user-driven and participatory approaches;

- integrated use of natural resources in ecosystem and farming systems;

- multi-level and multi-stakeholder involvement; and

- targeted policy support and institutional support, including development of incentive mechanisms for sustainable land management adoption and income generation at the local level.
Sustainable land use planning by way of sustainable land management applications requires collaboration and partnership at all levels. This collaboration should include the land users, technical experts and decision-makers in order to ensure that the causes of inappropriate land use planning and corrective measures such as frameworks and guidelines to sustainable land use planning are properly identified, applied and discussed.

The growing movement toward integrating participatory methods with GIS indicates that no individual approach currently meets society's changing information needs (Weiner, Harris et al. 2002; Mapedza, Wright et al. 2003; Mbile, DeGrande et al. 2003; Robiglio, Mala et al. 2003; Kienberger, Steinbruch et al. 2005, cited in Vajjhala [21]). Combining participatory mapping methods and GIS requires an assessment of their respective strengths and weaknesses for different applications and is essential for professionals such as development planners and community stakeholders alike (Vajjhala [21]). The participatory methods aided by GIS should have three attributes:

1. spatial and social objectives,

2. accuracy and precision in map displays, and

3. representativeness and comprehensiveness of spatial information.

Collectively, the three attributes of the mapping methods aided by GIS defines the fundamental process of integrating participatory mapping methods aided by GIS. The social aspect of the three attributes focuses primarily on the issues surrounding people as to how they live. The spatial aspect focuses on where (location) people live.

\section{Conclusions}

The main aim of this study, namely to produce frameworks and guidelines for participatory mapping aided by GIS technology, involving local community knowledge in sustainable land use management in Namibia, was achieved. Four frameworks with guidelines were provided where each framework shows examples of how participatory mapping can be incorporated such as sketch and photo-mapping.

The study confirmed that participatory approaches such as PRA, FGDs, sketch and photo-mapping can be used as tools for gathering data from local communities for sustainable LUP in Namibia. This opinion about sketch and photo-mapping is also supported by the results presented.

\section{Acknowledgements}

I am very grateful to the Namibia University of Science and Technology for the sabbatical leave. It allowed me sufficient time to complete this paper. 
Table 1. Frameworks and guidelines for participatory mapping aided by GIS in LUP in Namibia

\begin{tabular}{|l|}
\hline \multicolumn{1}{|c|}{ FRAMEWORK ONE: PREPARATORY WORK FOR PARTICIPATORY } \\
\hline \multicolumn{1}{|c|}{ Guidelines } \\
\hline Collect primary and secondary data about natural resources and socio-economic conditions. \\
Select site for participatory mapping according to identified objectives of ILUP. \\
Decide on size of participatory group discussions, 7 to 10 persons is recommended. \\
Select participants from the study area to represent the community population. \\
Choose the appropriate base map print-out or sketch, preferably an A0-size is recommended. With \\
regards to photo-mapping, scales depend on the desired level of detail and on local environmental \\
situation, but ideally should be approximately 1:5 000. \\
Use the transparency drawing papers to be fixed accurately on top of the base map (when dealing \\
with photo-mapping). For each land use, a separate transparency was used as it helps in looking at \\
the land use, as well as digitizing process and exporting data in digital format for later use in GIS. \\
A GPS receiver can complement data collection of boundaries (such as future plans, ownership) \\
for measurements of plots greater than 10 hectares. An instant verification of mapping results in \\
the field can be done with an additional transect walks within the surrounding areas.
\end{tabular}

Requirements

A coordinate system, grids, scale and a north arrow need to be printed on the base map. The map projection and map date should be indicated (when dealing with photo-mapping), as well as the name of the village.

Stationary: double clips to temporarily fix the transparencies securely on top of the aerial photographs [when dealing with photo-mapping], permanent and white board markers of different colours. A handheld GPS with accuracy up to five (5) metres is required.

\begin{tabular}{|c|c|}
\hline \multicolumn{2}{|l|}{ FRAMEWORK TWO: PARTICIPATORY MAPPING EXERCISES } \\
\hline Guidelines & Requirements \\
\hline $\begin{array}{l}\text { The village meeting should be scheduled for half a day to one day according to the specific } \\
\text { interests of the project and the size of the area to be mapped. A short introduction should provide: } \\
\text { the purpose of mapping the area (for example the land use to be mapped), } \\
\text { sufficient information about the approach of participatory mapping, } \\
\text { a brief explanation of the techniques to be used for mapping, } \\
\text { the year and month of publication on the base map used (if photo-mapping), and } \\
\text { An extra session should be conducted to answer any questions about the project. } \\
\text { Participants should have sufficient (about } 1 \text { hour) time to get familiar with the base map (if } \\
\text { photo-mapping). } \\
\text { Orientation could be facilitated through the identification of the location and the recognition of } \\
\text { easily identifiable landmarks such as towers, roads and residential areas. } \\
\text { Mapping activities should start with either important or easily recognisable features like major } \\
\text { infrastructure such as roads, hospitals and schools within the village. } \\
\text { The participants have to evaluate if land use changes occurred over time. Seasonal land use } \\
\text { changes need to be mapped as well. } \\
\text { Land use classifications have to be discussed and explained carefully before land use types are } \\
\text { being marked using agreed symbol set. } \\
\text { As the boundary is a legal entity of land, it is important that the positions of known boundaries are } \\
\text { marked accurately. } \\
\text { The facilitator should allow users to direct their own discussions. } \\
\text { The facilitator or an assistant should record the process and outcomes. }\end{array}$ & $\begin{array}{l}\text { Participants should be clearly informed } \\
\text { in advance about the purpose of } \\
\text { participatory mapping, and the place and } \\
\text { date of the meeting by sending out } \\
\text { letters. The meeting point should be on } \\
\text { an elevated vantage point with a good } \\
\text { view of the surrounding landscape. The } \\
\text { facilitator has to ensure that all users } \\
\text { have equal opportunities to participate in } \\
\text { discussions and express their real } \\
\text { opinion and expectations. } \\
\text { The facilitator should spend more time } \\
\text { listening than talking. }\end{array}$ \\
\hline \multicolumn{2}{|l|}{ FRAMEWORK THREE: DATA CAPTURING AND PROCESSING } \\
\hline Guidelines & Requirements \\
\hline $\begin{array}{l}\text { Spatial data should be entered into a GIS program by the GIS expert for further processing after } \\
\text { data collection through compiled participatory land use mapping. There are different options to } \\
\text { transfer the data to the GIS. Two options for this are: } \\
\text { to scan the papers for data transfer, and } \\
\text { onscreen digitizing of geographical features visible on the base map. } \\
\text { The projection system of the secondary GIS data should be the same as that of the aerial } \\
\text { photograph to be used for overlaying purpose. } \\
\text { Every vector feature of the resulting GIS data file (such as shapefile) need to have an identity code } \\
\text { (ID) for the land use class and one identity code for the local names. } \\
\text { Finally the map layout has to be designed. Cartographic conventions should be used for the } \\
\text { colour, and symbol sets; and cartographic elements such as map title, scale, coordinate grids and } \\
\text { the date of map compilation has to be added to the map. } \\
\text { The GIS data compiled from participatory mapping should be used to contribute to land use plans } \\
\text { and different land use maps. }\end{array}$ & $\begin{array}{l}\text { Small crosses should be drawn (with a } \\
\text { thin permanent pen) on the transparency } \\
\text { drawing paper at the intersections of the } \\
\text { coordinate system gridlines of the base } \\
\text { map. These crosses will be used to later } \\
\text { georeference the scanned transparency } \\
\text { paper map by using GIS software. }\end{array}$ \\
\hline \multicolumn{2}{|l|}{ FRAMEWORK FOUR: FEEDBACK TO STAKEHOLDERS } \\
\hline Guidelines & Requirements \\
\hline $\begin{array}{l}\text { After the data analysis and map compilation are finalised, a printout of the participatory } \\
\text { photo-map or sketch map should be taken back to the local communities so that the product can be } \\
\text { verified and be re-adjusted if necessary. } \\
\text { The original base map should be handed over to the villagers after data capturing has been done. } \\
\text { The sketch maps have to be handed back to the villagers or local communities for record keeping. }\end{array}$ & $\begin{array}{l}\text { Information to be provided on the map } \\
\text { should be the year and month of } \\
\text { compilation for the photo or sketch map; } \\
\text { the identified land boundaries; date of } \\
\text { data collection; a key to land use } \\
\text { categories; village name; and scale. } \\
\text { One copy of the sketch map should } \\
\text { remain in the village to be used as a } \\
\text { decision-making tool by villagers during } \\
\text { their village meetings. }\end{array}$ \\
\hline
\end{tabular}




\section{REFERENCES}

[1] Government of Namibia. Regional poverty profile: based on village-level participatory poverty assessment in Hardap region. Windhoek: National Planning Commission, 2006.

[2] Mendelsohn, J., Jarvis, A., Roberts, C. and Robertson, T. Atlas of Namibia: a portrait of the land and its people. Ministry of Environment and Tourism, Windhoek, 2002.

[3] Bonnett, A. What is Geography? London: SAGE Publications, 2008.

[4] Namibia Statistics Agency. Namibia 2011 Population and housing census basic report. Namibia Statistics Agency, Windhoek, 2013.

[5] Berg, L.B. Qualitative research methods for the social sciences. London: Allyn and Bacon, 1998.

[6] Bless, C. and Higson-Smith, C. Fundamental of social research methods: an African perspective. Third edition. Lusaka: Juta Publications, 2000.

[7] Mundia, L.C. The use of GIS in Flexible Land Tenure System (FLTS) at City of Windhoek - Namibia. Thesis (MSc). Vrije Universiteit Amsterdam, Online available from http://www.unigis.nl/downloads/msc/Lisho\%20Christoh\%20 Mundia.pdf

[8] Clifford, N, J., and Valentine, G. Key methods in geography. London: SAGE Publications, 2003.

[9] Mandara, C.G. Participatory GIS in mapping local context of conflicts over pastoral resources: a case study of Duru Haitemba, Babati, Tanzania. Thesis (MSc). Enschede, ITC, Online available from http://www.itc.nl/library/papers_2007/msc/nrm/mandara.pdf

[10] Minang, P.A. and McCall, M.K. Participatory GIS and local knowledge enhancement for community carbon forestry planning: an example from Cameroon, Online, Available from

http://www.communitycarbonforestry.org/NewPublications/ Participatory\%20GIS\%20and\%20local\%20-\%20Minang.pdf.

[11] Rambaldi, G., Chambers, R., McCall, M. and Fox J. Practical ethics for PGIS practitioners, facilitators, technology intermediaries and researchers, Online Available from http://www.ppgis.net/pdf/ch14_rambaldi_pp106-113.pdf

[12] Nethengwe, N.S. Integrating participatory gis and political

ecology to study flood vulnerability in the Limpopo Province of South Africa. Dissertation (PhD). West Virginia University, Online Available from

http://0-proquest.umi.com.oasis.unisa.ac.za/pqdweb?index $=1$ $2 \&$ did $=1467888251 \&$ SrchMode $=2 \&$ sid $=9 \&$ Fmt $=6 \&$ VInst $=$ PROD \&VType $=$ PQD\&RQT $=309 \&$ VName $=$ PQD $\&$ TS $=126$ 9944316\&clientId $=27625$

[13] Wageningen UR Centre for Development Innovation. Participatory Rural Appraisal (PRA), Online available from http://portals.wi.wur.nl/ppme/?Participatory Rural Appraisa 1_(PRA)

[14] Kumar, S. Methods for community participation: a complete guide for practitioners. New Delhi: Intermediate Technology Publications, 2002.

[15] Tripathi, N. and Bhattarya, S. Integrating indigenous knowledge and GIS for participatory natural resource management: state-of-the-practice. The Electronic Journal of Information Systems in Developing Countries (EJISDC). Vol. 17 (3) $1-13,2004$.

[16] Emery, A.R. Integrating indigenous knowledge in project planning and implementation. Canadian International Development Agency, Online available from http://www.acdi-cida.gc.ca/INET/IMAGES.NSF/vLUImage s/ea/\$file/IndiKnow-NP-e.pdf

[17] Craig, W.J. and Elwood, S.A. How and why community groups use maps and geographic information. Cartography and Geographic Information Systems. Vol. 25 (2) 95-105, 1998.

[18] Government of Namibia. Land use planning framework for the Kavango Region of Namibia within the Okavango river basin. Windhoek: Ministry of Lands and Resettlement, Online available from http://www.the-eis.com/data/literature/Kavango\%20land-use $\% 20$ planning\%20framework.pdf

[19] Amler, B., Betke, D., Eger, H., Ehrich, C., Kohler, A., Kutter, A., von Lossau, A., Müller, U., Seidemann, S., Steurer, R. and Zimmermann, W. Land use planning methods, strategies and tools - Eschborn, 1999, Online available from http://www.mpl.ird.fr/crea/taller-colombia/FAO/AGLL/pdfd ocs/gtz-lup.pdf

[20] Venema, J.H., Alim, M., Vargas, R.R., Oduori, S. and Ismail, A. Land use planning guidelines for Somaliland. Technical Project Report. Nairobi: FAO, 2009.

[21] Vajjhala, S.P. Integrating GIS and participatory mapping in community development planning. ESRI International User Conference, Sustainable Development and Humanitarian Affairs Track, July 2005, San Diego, CA. 